\title{
Validating Content of Sentence Variety Checklist for ESL Writing
}

\author{
Liza Abdullah \\ International Islamic University Malaysia, Kuala Lumpur, Malaysia \\ Email: liza_abdullah@iium.edu.my
}

\begin{abstract}
Zailani Jusoh
Faculty of Languages and Communication, Universiti Sultan Zainal Abidin (UniSZA), Terengganu Email: zailani@unisza.edu.my
\end{abstract}

\section{DOI: 10.6007/IJARPED/v6-i3/3164 URL: http://dx.doi.org/10.6007/IJARPED/v6-i3/3164}

\begin{abstract}
Sentence variety is a fundamental aspect in writing to avoid stereotypes, thus making writing more interesting. It is taken more seriously when it comes to assessment, compared to teaching. Students seem to be reluctant to learn more about it, and teachers are reluctant to teach (Saddler, 2007). With the intervention of sentence variety checklist (SVC) to promote sentence variety, this study investigated the validity of items in the SVC adapted from Langan (1993) to be justified, prior to its use in the ESL writing classroom. Five ESL teachers who are the writing experts and have been teaching writing for more than 15 years in a public university in Malaysia responded to the questionnaire of 14 items rephrased from the items in the checklist and one open-ended question for further suggestions. The data were analysed by computing Content Validity Index (CVI) using ratings of content item relevance by the writing experts. The results revealed that out of 14 items, 12 items were rated as highly relevant while the other two were still relevant. In addition, passive voice appeared to be another item suggested to be included in the checklist in the efforts to boost students' writing performance.

Keywords - ESL writing performance, Sentence Variety Checklist (SVC), Content Validity Index (CVI)

\section{INTRODUCTION}

"Variety is the spice of life." (McGraw-Hill Dictionary of American Idioms and Phrasal Verbs, 2002). To 'spice up' writing, sentence variety is an answer to it. Sentence variety is a fundamental aspect in writing to avoid stereotypes, thus making writing more interesting. The term sentence variety means using assorted sentence patterns, lengths, and rhythms (Battle, 2014). According to Herring (n.d), it is what gives writing better rhythm and flow, and makes writing sound more mature. Too many sentences with the same structure and length can grow monotonous for readers (https://owl.english.purdue.edu/owl/resource/573/01/, 2013). In addition, varying sentence styles and structures can also reduce repetition and add emphasis, hence keeping people interested in the writing and also helps them focus their attention to certain areas of the text or on certain facts.
\end{abstract}


As adding sentence variety to writing can enhance the flow of ideas, intensify points, and sustain the interest of readers, it is fair to state that it could be one of the ways to enhance students' writing performance. However, in many cases, Saddler (2010) claims that despite being vital in writing, students seem to be reluctant to learn more about it, and teachers are reluctant to teach, because they feel it is so "boring," and most of the time both groups think that as long as there are no grammatical errors in writing, it is "okay." Saddler also added that sentence variety has always been sidelined in many courses or workshops conducted for English Language instructors. As such, it is imperative to examine the effect of incorporating sentence variety in teaching on ESL students' writing performance.

To incorporate sentence variety in the teaching methodology, the researcher constructed a checklist (Appendix 1) called Sentence Variety Checklist (SVC) comprises items adapted from Langan's 'College Writing Skills' book (1993) to be used as an intervention in teaching writing to the ESL students in the International Islamic University Malaysia. Even though they are adapted, the items still have to go through validation process before its use.

In order to ensure the pedagogical potentials of the SVC as a research instrument, this instrument had to be assessed prior to using, for its validity. A systematic approach to establishing validity and reliability of a research instrument is required (Malgreen, 2005), and one of the ways suggested by Malgreen is selecting content experts to review the relevance and clarity. The purpose of this study therefore is to verify the items of the Sentence variety checklist by writing experts for possible modifications before employing it in the ESL writing classroom. Hence, the study is expected to shed light on the following research questions:

1. Are the items in the SVC relevant for ESL students to boost their writing performance?

2. Which items in the SVC are not highly relevant for ESL students to boost their writing performance?

3. What are other possible items to be included to improvise the SVC?

This study is hoped to be able to give insights to the researcher in investigating the weight of importance of the items included in the SVC. It is also expected to determine whether there is a ground to emphasize sentence varieties in students' writing to avoid sentences with the same structure and length which can grow monotonous for readers.

The literature related to this study comes in two forms. The first one is on content validity, while the other one is on writing assessment sub-skills. The former is essential to understand the method of validating the content of the research instrument and the latter is to pre-determine the important sub-skills entailed in writing assessment. Polit and Beck (2006) defined Content Validity Index (CVI) as an approach involves having a team of experts indicate whether each item on a scale is relevant to the construct, computing the percentage of items deemed to be relevant to each expert, and taking and average of the percentages across experts (Polit \& Beck, 2006). According to Lynn (1986) as cited from Polit and Beck (2006), there are two types of CVIs which are I-CVI that is content validity for individual items and the other one is S-CVI which is for overall scale. Lynn also advised a minimum of three experts, but indicated that more than 10 may not be necessary. The items ratings are typically on a 4-point 
ordinal scale but 3- or 5-point rating scales can also be considered. Nevertheless, she advocated using a 4-point scale to avoid having a neutral and ambivalent midpoint. Several different labels for the four points along the item-rating continuum have appeared in the literature, but the one frequently used is $1=$ not relevant, 2 =somewhat relevant, $3=$ =quite relevant, and $4=$ highly relevant. The results depend on the average of responses given by all raters for each item.

As far as ESL writing assessment is concerned, most researchers tend to place the position language ability against the topical knowledge, in which Weigle (2002) in her book, Assessing Writing stresses that language ability should be the one that we are interested in, in a language test, not the other components of language use that are involved in actual communication, namely topical knowledge. As such, topical knowledge may or may not be specifically assessed in a writing test and may or may not be part of the construct being measured.

Bachman and Palmer (1996) have somewhat partial agreement when they are in the opinion that there are three fundamental options for defining the construct with respect to topical knowledge: specifically excluding topical knowledge from the construct, including both language ability and topical knowledge in the construct definition, and defining language ability and topical knowledge as separate constructs. They, however add that the option selected will be based on the specific purpose of the test, for example, Hughes (1989) argues that in general language proficiency testing, writing tasks that require examinees to use their own content knowledge should not be used. On the other hand, topical knowledge is one of the distinctive features of language for specific purposes (LSP) testing.

To look at the relevance of the items in the SVC, it is also worthwhile to look at the subskills required in the writing assessment of the International English Language Testing System (IELTS) which have been used to assess the language ability of candidates who need to study at the post-secondary or university level or work in a professional capacity where English is used as the language of communication.

These ideas from those relevant scholars and prominent test would give more insights to the researcher in justifying the fact that emphasis should be put more on the language aspects as included in the SVC. In addition, the items or constructs are expected to be validated systematically via the Content Validity Index.

\section{METHODOLOGY}

\section{Participants}

A total of five ESL English Language instructors in the International Islamic University Malaysia, Malaysia were selected to be respondents for the study. They are ESL English Language instructors who have been teaching for more than 15 years, and are considered as the content experts due to wide experience in teaching as well as the various writing courses taught over the years.

\section{Research Instruments}

The tool used to validate the items in the SVC was a set of questionnaire formulated based on the 14 items in the SVC as displayed in Appendix 2. Adapting from Lynn (1986), the 
items had been rephrased and put in a scale form for the experts to respond by giving the degree: 1, 2, 3, and 4 (1 Not relevant, 2 Somehow relevant, 3 Quite Relevant, 4 Highly Relevant). The questionnaire also consisted of one open-ended question in which the respondents were requested to provide other possible items to be included in the SVC.

\section{Procedure}

Quantitative methodology was employed in collecting the data to answer the research questions. The questionnaires were then sent to the 5 respondents online via google.docs and the responses were returned online in less than 2 days.

\section{Data Analysis}

Data obtained were then gathered and keyed into Excel to be analysed by computing Content Validity Index (CVI) using ratings of content item relevance by the writing experts.

The data to address the first research question of this study were analysed by S-CVI while the data for the second research question were addressed by the results revealed through the process of I-CVI. The results were expected to shed some light in validating the items adapted to be incorporated in the checklist.

\section{RESULTS AND DISCUSSIONS}

Table 1. Ratings on a 14-Item Scale by Five Experts: Items Rated 3 or 4 on a 4-Point Relevance Scale (anything below 3 is considered not relevant)

$\begin{array}{cccccccc}\text { Item } & \text { Rater 1 } & \text { Rater 2 } & \text { Rater 3 } & \text { Rater 4 } & \text { Rater 5 } & \begin{array}{c}\text { No.of } \\ \text { Agreement }\end{array} & \text { Item CVI } \\ 1 & 4 & 4 & 4 & 4 & 4 & 5 & 1 \\ 2 & 4 & 4 & 4 & 4 & 4 & 5 & 1 \\ 3 & 3 & 3 & 4 & 3 & 3 & 5 & 1 \\ 4 & 3 & 3 & 1 & 3 & 4 & 4 & 0.8 \\ 5 & 3 & 3 & 3 & 3 & 3 & 5 & 1 \\ 6 & 3 & 3 & 4 & 3 & 4 & 5 & 1 \\ 7 & 4 & 3 & 4 & 4 & 4 & 5 & 1 \\ 8 & 4 & 3 & 4 & 4 & 4 & 5 & 1 \\ 9 & 4 & 3 & 4 & 4 & 4 & 5 & 1 \\ 10 & 4 & 3 & 4 & 3 & 4 & 5 & 1 \\ 11 & 4 & 3 & 4 & 4 & 4 & 5 & 1 \\ 12 & 4 & 4 & 4 & 3 & 4 & 5 & 1 \\ 13 & 4 & 4 & 4 & 4 & 4 & 5 & 1 \\ 14 & 4 & 4 & 2 & 3 & 3 & 4 & 0.8 \\ \text { Proportion } & & & & & & \text { Mean I-CVI=0.971 } \\ \text { Relevant: } & & & & & & & \text { S-CVI/UA=1.2 }\end{array}$

I-CVI, Item-level content validity index

$\mathrm{S}-\mathrm{CVI}$, Scale-level content validity index, universal agreement calculation method. 
Research Question 1: Are the items in the SVC relevant for ESL students to boost their writing performance?

According to the data in the content validity index in Table 1, the items included in the SVC are highly relevant. This is shown by the mean of I-CVI $=0.971$ and S-CVI/Ave of 1.2 which are congruent with Lynn's criteria (1986) as cited from Polit and Beck (2006) that states that I$\mathrm{CVI}=1.00$ is required from 3 to 5 experts and $\mathrm{S}-\mathrm{CVI} /$ Ave of .90 or higher.

As far as writing assessment is concerned, the items in the SVC are highly important to be emphasized to gauge ESL students' writing ability. These findings are consistent with what Weigle (2002) reiterated that in a language test, language ability is the one that we should be focusing on, not the other components of language use, namely topical knowledge. They also justify the view of Bachman and Palmer's (1996) that suggested in a writing assessment, we should be given options whether to test topical knowledge since the main concern in the assessment is language ability. Finally, the SVC items can also be a substantial basis to Hughes' (1989) idea that was in favour of not using content knowledge in a writing assessment, but only to focus on students' language ability.

Therefore, it can be inferred that we can always provide content in a writing assessment and what students should do is to demonstrate their language ability based on the content given.

Research Question 2: Which items in the SVC are not highly relevant for ESL students to boost their writing performance?

Based on the results in Table 1, items 4 and 14 are found to be not as relevant as other items. Item 4 from the questionnaire is 'The essay should consist of sentences of different patterns which are simple, compound and complex'; while item 14 is 'The essay should consist usage of ellipsis by omitting certain words to avoid wordiness'. The result revealed for item 4 is rather alarming since this is one of the commonly required sub-skills in the English writing marking rubrics. The ability to write using varieties of sentence patterns is also required by IELTS to gauge students' writing performance. Item 14 is rated not as relevant may due to the fact that it might be hard to teach ellipsis and on top of that it is at all required by the curriculum. According to Roberts (2013), ellipsis is something which is often dealt with in 'advanced' level materials. Therefore, it needs to be considered especially for the groups of higher levels regardless of the fact that it has not been 'spelled out' even in the IELTS Writing Descriptors.

\section{Research Question 3: What are other possible items to be included to improvise the SVC?}

From the open-ended question, two raters suggested to include passive voice in the SVC. The reason the researcher did not include Passive voice in the SVC at the initial stage of this study for a lot of scholars are generally not keen on looking at students' ability in writing from the aspect of passives. As claimed by Rhodes (1997), despite the fact that some characteristics of the passive voice have been explored in terms of its transformational properties, others such as the way that passives are used in context, have received less attention. Nevertheless, this particular finding of this study does make sense as Rhodes (1997) further elaborated that: 
although short, isolated, narrative active voice sentences (e.g., Jack threw the ball.) were shown three decades ago to require less efforts to process than their passive counterparts (e.g., The ball was thrown by Jack.), it does not follow, nor has it been empirically demonstrated that passive sentences that are longer, contextually-appropriate, and non-narrative are either processed more slowly or understood less well than active sentences. In fact a number of subsequent studies have shown that contextuallyappropriate passive verbs are processed as easily as active verbs. (p.2)

This is also supported by Wilkinson (1992) who claimed that passive voice is suitable for scientific writing. Rodman (1994) also described the advantages of using passive voice for describing scientific procedures. Studies also show that using the passive voice is a stylistic and rhetorical choice, often used for the purpose of reporting hard facts and observations (Dumin, 2010).

The literature above somehow justifies the idea to incorporate the passives in the SVC. As students of the university are preparing themselves for degree levels, it is imperative to observe their ability to write using passive voice as well, to ensure they can apply it in their more technical and scientific writing in the future.

\section{CONCLUSION}

To conclude, this study has examined the validity of items in the sentence variety checklist (SVC) developed by the researcher based on the content of Langan's book, College Writing Skills (1993). Among all the 14 items included, 12 of them are rated as highly relevant while the other 2 are rated lower in terms of their validity. This indicates that it is imperative to emphasize the items in teaching as they are proven to be essential in demonstrating students' higher ability in writing. In addition, another item which is passive form has been suggested to be included in the SVC as well.

These findings, therefore imply that there is a high justification to employ the SVC with some modifications as illustrated in Appendix 2. Finally, it is strongly recommended that SVC be employed in the writing curriculum for intermediate level and higher to support ESL students in making their writing more mature and interesting. In promoting the items, instructors should focus on students' ability in creating better and more meaningful sentences, rather than spending so much time editing the work on spelling mistakes or other technical problems.

\section{REFERENCES}

Bachman, L.F. \& Palmer, A.S. (1996). Language testing in practice: Designing and developing useful language texts. Oxford: Oxford University Press.

Battle, D. (2014). Sentence Variety. https://prezi.com/4dsevlictcde/sentence-variety

Collier, L.C., (2014). "Good Writing” in Increasingly Internationalized U.S. Universities: How Instructors Evaluate Different Written Varieties of English. ProQuest LLC. 
Combs, W.E. (1975). Some further effects and implications of sentence combining exercises for the Secondary language arts curriculum (Doctoral dissertation, University of Minnesota, Twin Cities, 1975) Dissertation Abstracts International 36, A1266.

Dumin, L.M. (2010). Changes in the use of passive voice overtime: A historical look at the "American Journal of Botany" and the changes in the use of passive voice from 19142008. Oklahoma State University. ProQuest Dissertations Publishing.

Herring, D (n.d.) What is Sentence Variety? https://www.blinn.edu/humanities/writingroom/Sentence\%2520Variety\%2520WR.ppt. Brenham Writing Room

Hughes, A. (1989). Testing for Language Teachers. Cambridge: Cambridge University Press.

Langan, J. (1993). College Writing Skills. McGraw Hill.

Lynn, M.R. (1986). Determination and quantification of content validity. Nursing Research, 35, 382-386.

Malgreen, C. (2005). Validating Research Instruments. National Nursing Staff Development Organisation.

McGraw-Hill Dictionary of American Idioms and Phrasal Verbs, 2002

Polit, D.F \& Beck, C.T (2006). The Content Validity Index: Are You Sure You Know What's Being Reported? Critique and Recommendations. Wiley Periodicals, Inc.

Purdue OWL, Sentence Variety (2013) https://owl.english.purdue.edu/owl/resource/573/01

Roberts, R. (2013). Am I missing something? Raising awareness of ellipsis and substitutions. Presentation at IATEFL 13.

Rodman, L. (1994). The active voice in scientific article: Frequency and discourse functions. Journal of Technical Writing and Communication, 24, 309-331

Rhodes, S. (1997). The Active and Passive Voice are Equally Comprehensible in Scientific Writing. UMI, A Bell and Howell Information Company

Saddler, B. \& Saddler, K.A. (2010) .Writing Better Sentences: Sentence-Combining Instruction in the Classroom.

Scott, C.M. \& Balthazar, C. (2013). The Role of Complex Sentence Knowledge in Children with Reading and Writing Difficulties. Perspectives on Language and Literacy. 
ProQuest.

Scott, C.M. \& Nelson, N.W. (2009) Sentence Combining. Assessment and Intervention Applications. Perspectives on Language Learning and Education. ProQuest.

Weigle, S.C (2002) Assessing Writing. Cambridge University Press.

Wilkinson, A.M. (1992). Jargon and the Passive Voice: Prescriptions and Proscriptions for Scientific Writing. Retrieved from https.//journal.sagepub.com/doi/abs/ 


\section{Appendix 1}

\section{Sentence Variety Guideline/Checklist}

\section{Use this guideline in writing your essay.}

\begin{tabular}{|c|c|c|c|}
\hline No. & $\begin{array}{l}\text { My essay consists of } \\
\text { sentences that: }\end{array}$ & Examples: & $\begin{array}{l}\text { Tick if } \\
\text { you have }\end{array}$ \\
\hline 1 & are different in length & & \\
\hline 2 & $\begin{array}{l}\text { are different in types: } \\
\text { simple } \\
\text { Compound }\end{array}$ & $\begin{array}{l}\text { My brother's car broke down yesterday. } \\
\text { My brother had been working on the engine for } 2 \\
\text { hours, but the car still wouldn't start. } \\
\text { Because the car wouldn't start, he had to call a } \\
\text { mechanic to come to our house. }\end{array}$ & \\
\hline 3 & $\begin{array}{l}\text { begin with special } \\
\text { words: } \\
\text {-ed word } \\
\text {-ing word } \\
\text {-ly words } \\
\text { to word group } \\
\text { prepositional phrase }\end{array}$ & $\begin{array}{l}\text { Excited by the good news, Khadijah called her } \\
\text { mother immediately. } \\
\frac{\text { Walking anxiously, Aminah kept looking for her }}{\text { missing cat. }} \\
\text { Reluctantly, Ali left for Japan to further his } \\
\text { studies. } \\
\text { To pass the exam, you have to do a lot of } \\
\text { During the exam, drops of water fell from the } \\
\text { ceiling. }\end{array}$ & \\
\hline 4 & $\begin{array}{l}\text { have adjectives and } \\
\text { verbs placed in a series } \\
\text { adjectives } \\
\text { verbs }\end{array}$ & $\begin{array}{l}\text { Ahmad is a loving husband, caring father, loyal } \\
\text { friend and efficient worker. } \\
\text { The baby crawled on a carpet, picked up a button } \\
\text { and put it in his mouth. }\end{array}$ & \\
\hline 5 & $\begin{array}{l}\text { are to replace nouns } \\
\text { with pronouns }\end{array}$ & $\begin{array}{l}\text { Aminah is a very dedicated, committed and } \\
\text { hardworking employee. She has been working for } \\
\text { IIUM for almost } 20 \text { years and has been holding a } \\
\text { lot of posts apart from teaching... }\end{array}$ & \\
\hline 6 & use synonyms to replace & Aminah is a very dedicated, committed and & \\
\hline
\end{tabular}




\begin{tabular}{|c|c|c|}
\hline & some words & $\begin{array}{l}\text { hardworking employee/staff/worker. She has } \\
\text { been working for IIUM for almost } 20 \text { years and } \\
\text { has been holding a lot of posts apart from } \\
\text { teaching.. }\end{array}$ \\
\hline 7 & $\begin{array}{l}\text { Use different transition } \\
\text { signals }\end{array}$ & $\begin{array}{l}\text { The first reason is of traffic problem is..... } \\
\text { In addition to..........can be a cause of traffic } \\
\text { problem. } \\
\text { In contrast, on the other hand, nevertheless, } \\
\text { nontheless } \\
\text { So, as a result, as a consequence, consequently } \\
\text { etc }\end{array}$ \\
\hline 8 & $\begin{array}{l}\text { Omit some words or } \\
\text { phrases to avoid } \\
\text { wordiness/ellipsis }\end{array}$ & $\begin{array}{l}\text { Some people enjoy interacting with other people } \\
\text { who they do not know while others may do so for } \\
\text { the sake of businesses or education. } \\
\text { Those houses are my houses or those houses are } \\
\text { mine. }\end{array}$ \\
\hline
\end{tabular}

Adapted from College Writing Skills With Reading (John Langan, 1993) 